\section{The Leonardo Laboratory}

FEw of the major works of Leonardo da Vinci survived even his lifetime, and his reputation rests in large part on the annotated drawings that contain the record of his artistic and scientific development. The best collection of Leonardo drawings, which includes almost all the anatomical works, is that in the Queen's possession, and much of it is now on public display in the Queen's Gallery at Buckingham Palace.

Leonardo was born in 1452, the bastard son of a notary and a peasant girl, who after the affair married a cowherd. Leonardo was later accepted into his own father's family but received little formal education. Most of his early life was spent in Florence where his chief energies were devoted to painting and sculpture;

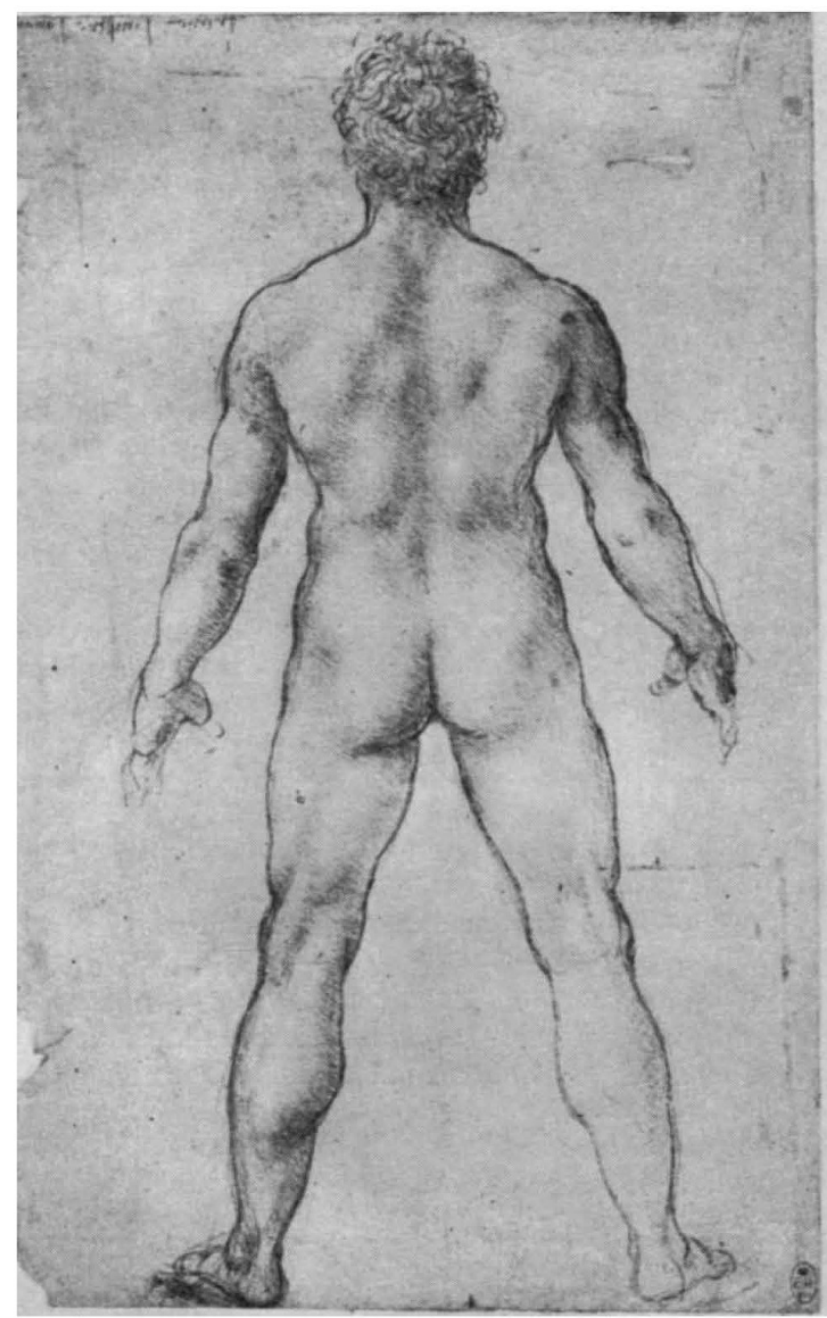

time was left, however, for the awakening of his interest in anatomy, geology, botany and mechanics. As military engineer to the Duke of Milan from 1482 to 1499, Leonardo had the leisure to perform the dissections on which his anatomical drawings are based. After a second period in Milan he spent an unhappy four years in Rome, left for France in 1517 and died two years later at the Chateau of Cloux on the Loire.

Because Leonardo did not live to publish his discoveries, his influence on the history of scientific thought was considerably less than the evidence of his manuscripts suggests it could have been. He was dropping weights off towers a hundred years before Galileo is supposed to have performed the same experiment, and long before the doctrine of geocentrism was abandoned he concluded that the Sun does not move.

Perhaps the most notable of his scientific achievements lay in his study of anatomy. Although some of his early drawings repeat the mistakes of Galen's physiology, he described many structures with an accuracy that was not surpassed until well into the 17th century. His objective was to show the human body as a machine, which is why the diagrams and annotations on the drawings are imbued with the mechanical ideas he had developed. He would perhaps have anticipated Harvey if he had not carried over to anatomy his observations on the movement of water and eddy currents; he believed that the force with which the blood is pumped from the heart would have been dissipated by eddy currents at the time it reached the end of the arterial system and hence he had no reason on these grounds to suppose that there was a circulation.

Leonardo's interest in anatomy may have been awakened by an executed head he was given to dissect. $\mathrm{He}$ is said to have dissected some thirty bodies in the course of his work, although some of the drawings, according to Dr K. D. Keele, are in fact based on animal anatomy (Leonardo on the Movement of the Heart and Blood, Harvey and Blythe, 1952).

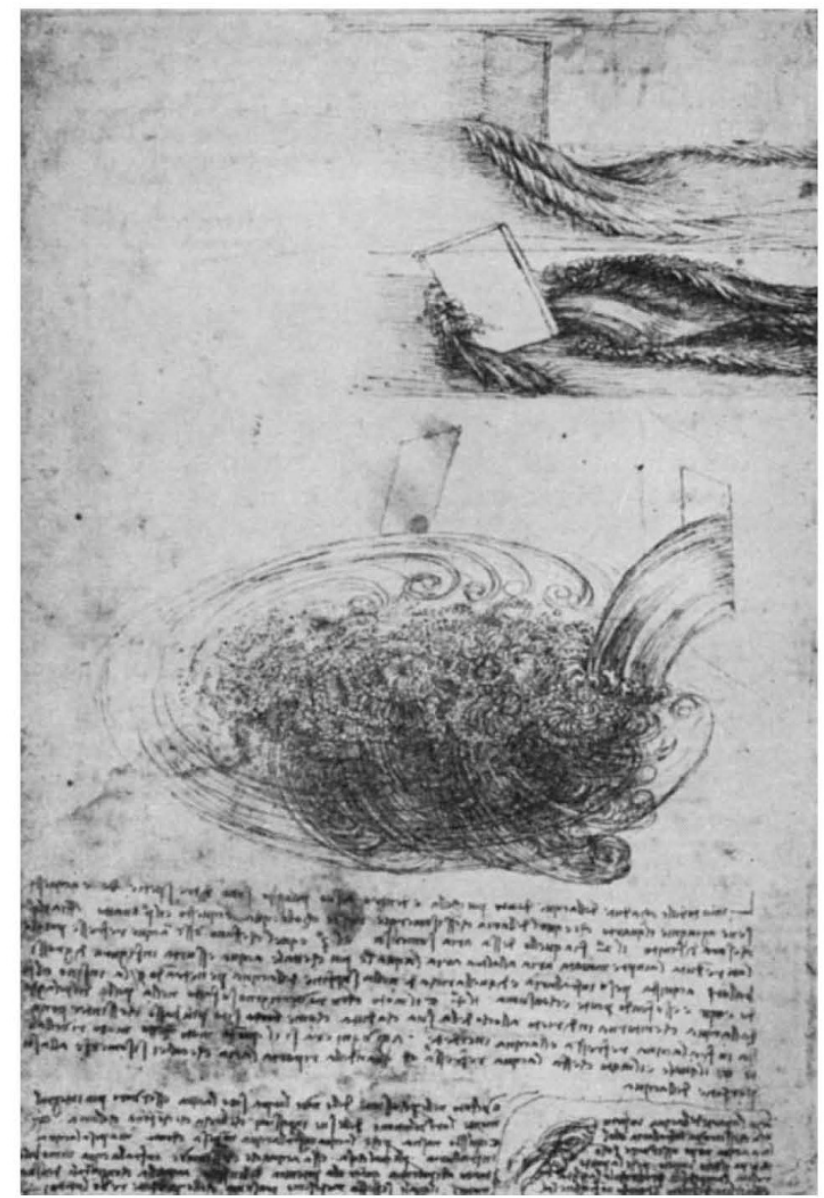

